immunization was performed under continuous cardiorespiratory monitoring.

Conclusions Preterm infants who received diphtheria-tetanuspertussis-inactivated polio-Haemophilus influenzae type B and pneumococcal vaccine before discharge were more likely to temporarily experience prolonged apnea and bradycardia after immunization. Continuous mobile event monitoring of these infants was a helpful tool to detect clinically significant cardiorespiratory events.

\section{EASY FOR YOU TO SAY! ADHERENCE ISSUES IN ADOLESCENCE}

doi:10.1136/archdischild-2012-302724.0081

JC Suris. Department of Pediatrics, Lausanne University Hospital, Lausanne, Switzerland

Adherence to treatment (defined as the active, voluntary, collaborative involvement of the patient in a mutually acceptable course of behavior to produce a desired preventive or therapeutic result) is not always simple, and for adolescents suffering from chronic conditions even less.

Adolescence is a time of transitions: from childhood to adulthood, from education to employment, from pediatrics to adult health, from controlled treatment to treatment control. This means that they have to manage their treatment (which may cause problems with their parents who had this function until then) and have the right to disagree (which may cause problems with their health care providers).

In fact, among adolescents with chronic diseases, treatment adherence rates vary widely depending on the condition: from $98-99 \%$ for cancer to $77 \%$ for mild asthma or $55-86 \%$ for renal transplant recipients, for example. Nevertheless, and although selfreport is often overestimated, part of the variation among adherence rates is also due to what kind of cut-off point for good/ acceptable adherence is used.

Although there are many factors influencing adherence (such as side effects, taste, motivation or severity of the condition to mention a few), there is fair amount of literature related to the predictors of a good or a poor adherence. This presentation will explore the main causes of non-adherence among youths and practical and relatively simple ways to increase their adherence rate.

\section{STABILITY OF LUNG FUNCTION TESTS BETWEEN 8 AND 18 YEARS OF AGE OF EPT/ELBW SURVIVORS COMPARED WITH TERM CONTROLS}

doi:10.1136/archdischild-2012-302724.0082

1.2.3LW Doyle, ${ }^{4} \mathrm{~A}$ Gibson, ${ }^{\mathrm{J}}$ Cheong, ${ }^{4} \mathrm{G}$ Roberts, ${ }^{4} \mathrm{C}$ Robertson, The Victorian Infant Collaborative Study Group. 'Royal Women's Hospital; ' ${ }^{2}$ nniversity of Melbourne; ${ }^{3}$ Murdoch Children's Research Institute; ${ }^{4}$ Royal Childrens Hospital Melbourne, Parkville, VIC, Australia

Aims To determine the stability of lung function test results of extremely preterm (EPT; $<28$ weeks' gestational age) or extremely low birthweight (ELBW; birthweight $<1000 \mathrm{~g}$ ) survivors between 8 and 18 years of age compared with term controls.

Methods Eighteen-year follow-up of participants born either EPT/ELBW in 1991-92 in the state of Victoria and randomly selected term, normal birthweight controls. Lung volumes and flows, including the forced expired volume in 1 second $\left(\mathrm{FEV}_{1}\right)$, forced vital capacity (FVC), the $\mathrm{FEV}_{1} / \mathrm{FVC}$, and the forced expiratory flow $\left(\mathrm{FEF}_{25-75 \%}\right)$ were measured at 8 and 18 years of age according to standard guidelines and results converted to Z-scores for age, height and gender.
Results Lung function data were obtained from 187/298 (63\%) EPT/ELBW subjects and 147/262 (56\%) controls at both 8 and 18 years. There were strong positive relationships between lung function results at 18 years with results obtained at 8 years in both groups (Table).

\section{Abstract 82 Table 1}

\begin{tabular}{lcccc}
\hline Lung function variable & EPT/ELBW & \% variance & Controls & \% variance \\
\hline FEV1 & $0.887(0.058)^{*}$ & $56.0 \%$ & $0.554(0.071)^{*}$ & $29.4 \%$ \\
FVC & $0.676(0.058)^{*}$ & $42.2 \%$ & $0.586(0.067)^{*}$ & $34.5 \%$ \\
FEV1/FVC & $0.422(0.051)^{*}$ & $26.8 \%$ & $0.384(0.063)^{*}$ & $20.5 \%$ \\
FEF25\%-75\% & $0.772(0.057)^{*}$ & $50.3 \%$ & $0.561(0.070)^{*}$ & $30.7 \%$ \\
\hline
\end{tabular}

Changes in Respiratory Variables Between 8 and 18

Data are regression coefficients $(\mathrm{SE}) ;{ }^{*} P<0.001$

Relationships between 8 and 18 years were significantly stronger for EPT/ELBW subjects for both $\mathrm{FEV}_{1}$ and $\mathrm{FEF}_{25-75 \%}$ compared with controls.

Conclusions There are strong linear relationships between lung function values at 8 and 18 years in both EPT/ELBW survivors and controls.

\section{LEVEL OF SELF-SUFFICIENCY OF YOUNG PEOPLE WITH DOWN SYNDROME (AGE 16-19 YEARS OLD)}

doi:10.1136/archdischild-2012-302724.0083

M Fekkes, H van Gameren-Oosterom, J van Wouwe. TNO Child Health, TNO, Leiden Belgium

Background and aims Becoming independent is for young people with Down syndrome (DS) not a standard development, because of their intellectual impairment. Parents often wonder what level their child with DS might reach. This study aims to measure the level of self-sufficiency and problem behaviour in a large population based sample of 16-19-year-old people with DS

Methods Parents of Dutch children with DS born in 1992, 1993 and 1994 were invited to participate $(n=513)$. Data were collected by a written questionnaire for the parents, containing the Dutch SRZ (measuring social independence), the Child Behaviour Checklist, the Children's Social Behaviour Questionnaire, and additional questions on skills and background. Differences between mean values were evaluated using t-tests.

Results Mean age of the 322 participating young people with DS was 18.3 years $(52.8 \%$ boys). Considering their basic daily skills, they reached a level of around $70 \%$ of independent functioning. Girls had a higher level of functioning than boys ( $<<0.001)$, except for the subscale social orientation. With regards to behaviour problems the young people with DS had more behavioural problems on the subscales social problems, thought problems and attention problems. Only on the subscale anxious/depressed young people with DS scored fewer problems $(p<0.001)$. Social problems were most present in the subscales orientation problems, not understanding social situations, and resistance to changes.

Conclusions Young people with DS do not reach a complete level of independent functioning. Behavioural and social problems have an important contribution to the limited self-sufficiency of this group.

\section{HOW CAN WE IMPROVE TISSUE PERFUSION AFTER CARDIAC SURGERY}

doi:10.1136/archdischild-2012-302724.0084

E da Cruz. Pediatrics, Children's Hospital Colorado, University of Colorado Denver, School of Medicine, Aurora, CO, USA 